\title{
Nuevas consideraciones en torno a un monumento pétreo de la Estructura IV-B de Calakmul
}

\section{New Considerations about a Stone Monument from Structure IV-B of Calakmul}

\author{
Pablo Alberto Mumary Farto \\ Programa de Becas Posdoctorales, Instituto de Investigaciones Antropológicas, \\ Universidad Nacional Autónoma de México, México
}

\begin{abstract}
Resumen: A finales de la década de los noventa del siglo xx, en los informes arqueológicos del Proyecto Arqueológico Calakmul se reportó un monumento inacabado, catalogado como Estela 117 por Martin al ser encontrado en la Estructura IV. En su parte frontal, los cartuchos jeroglíficos conservados no contienen información al no haber sido tallados, aunque todavía se distingue la representación de un personaje que porta atributos guerreros, sentado sobre un trono situado encima de un basamento formado por un monstruo witz con nombre toponímico. En la cédula informativa que se exhibe en el Museo de la Arquitectura Maya del Baluarte de la Soledad (en la ciudad de Campeche, México) donde se encuentra resguardado, se indica que es un "Dintel del Clásico Temprano en el que se representa al gobernante K'altun Hix”, quien fue uno de los ajawtaak tempranos de la dinastía Kaan. Sin embargo, formalmente el monumento no parece corresponder con un dintel, estilísticamente no coincide con la cronología propuesta y, además, la dinastía Kaan todavía no estaba asentada en Calakmul durante el Clásico Temprano. Por ello, a través del análisis iconográfico del monumento, haciendo hincapié en los elementos simbólicos que todavía se conservan y teniendo en cuenta el contexto arqueológico e histórico de la Estructura IV, se discute la posible temporalidad, el tipo de monumento y quién pudo ser el personaje representado.
\end{abstract}

Palabras Clave: Calakmul; Estructura IV-B; dinastía Kaan; escultura; iconografía maya.

ABstract: At the end of the decade of the 90's of the 20th century, the Calakmul Archaeological Project reported an unfinished monument, listed by Martin as Stela 117, which was found in Structure IV. On the front, the hieroglyphics were uncarved, but still show a figure carrying warrior attributes sitting on a throne located on 
the top of a witz basement with a toponymic name. In the monument's informative card at the Museo de la Arquitectura Maya of the Baluarte de la Soledad (in Campeche, México) where it is exhibited, mentions that it's an "Early Classic lintel in which it's represented K'altun Hix" who was one of the early ajawtaak of the Kaan dynasty. However, formally the monument does not seems like a lintel, stylistically it does not coincide with the proposed chronology and, also, the Kaan dynasty was not installed in Calakmul yet during the Early Classic. Therefore, through the iconographic analysis of the monument, with and emphasis on the symbolic elements that are still preserved and taking into account the historical and archaeological context of the Structure IV, we will discuss the possible temporality, the type of monument and who the character represented could be.

KeYworDs: Calakmul; Structure IV-B; Kaan dynasty; sculpture; Maya iconography.

RECEPCIÓN: 28 de agosto de 2019.

ACEPTACIÓN: 10 de febrero de 2020.

Dol: https://doi.org/10.19130/iifl.ecm.2020.56.2.0001

\section{Antecedentes}

En 1932, tras haber recibido previamente los informes de Cyrus Lundell sobre el redescubrimiento del sitio prehispánico de Calakmul, Sylvanus Morley encabezó la expedición hacia el asentamiento ubicado en el sur del actual estado mexicano de Campeche. En esta primera exploración, su equipo registró 103 estelas y, a pesar del volumen de monumentos, el investigador apuntaba que "ninguna de las estelas tiene mérito artístico, el énfasis había estado en la cantidad y no en la calidad” (Lister y Lister, 1970: 144; traducción mía). Años más tarde, Karl Ruppert y John Denison (1943) realizaron una descripción y un mapa más detallado del sitio arqueológico ubicando, por ejemplo, la Estructura IV dentro del Grupo Suroeste. Casi 40 años después, el Proyecto Arqueológico Calakmul de la Universidad Autónoma de Campeche encabezado por William Folan y apoyado por el doctor Román Piña Chan, iniciaría nuevos trabajos arqueológicos sistemáticos en la antigua ciudad (Martínez, 1990).

En este contexto se llevaron a cabo los trabajos en la llamada Gran Plaza de Calakmul, compuesta por diversas construcciones entre las que se encuentra la Estructura IV (Figura 1) que, en la actualidad, se configura como una larga plataforma en la que se disponen tres basamentos piramidales comunicados entre sí por andadores (Carrasco, 2003: 151). Ya en los años cuarenta del siglo xx Ruppert y Denison advertían sobre su importancia, clasificándola como un conjunto que formaría un Grupo E junto con la Estructura VI, que se encuentra en frente (Ruppert y Denison, 1943: 19), y cuyos fines podrían estar asociados a actividades de observación astronómica, algo que ha sido puesto en duda por otros investigadores (Nieves, Esparza y García, 1995; Šprajc y Sánchez, 2012). Asimismo, destacaba 
la presencia de un gran número de estelas y altares en sus distintas secciones: IV-A, IV-B y IV-C.

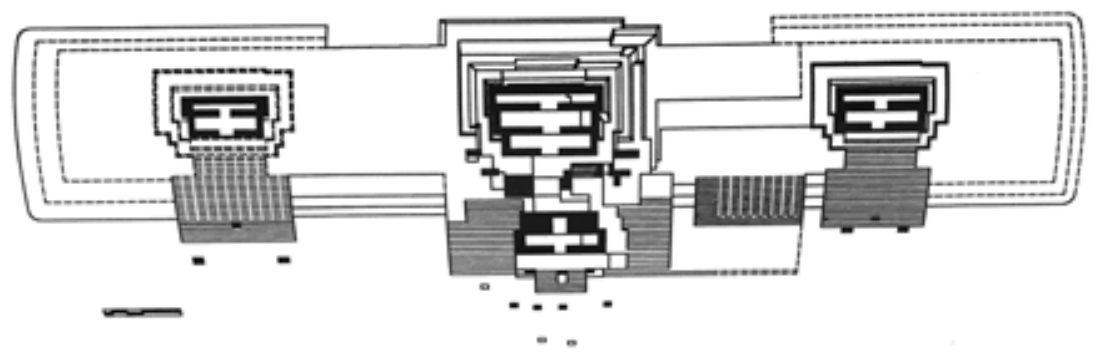

Figura 1. Plano arquitectónico de la Estructura IV de Calakmul (Tomado de Carrasco, 1999: 4).

Los diferentes trabajos arqueológicos realizados en la estructura, tanto por el equipo de Folan como, posteriormente, por el Proyecto Arqueológico Calakmul adscrito al Instituto Nacional de Antropología e Historia y dirigido por Ramón Carrasco desde los años iniciales de la década de los noventa del siglo xx, han mostrado una larga secuencia de actividad (Clásico Temprano-Clásico Tardío) en la que destacan los descubrimientos de entierros y depósitos rituales (Vázquez, 2014), así como la presencia de estelas y altares circulares cuyas temporalidades abarcan del siglo vII al viII d.C. Sus diferentes remodelaciones constructivas son las que le confieren su aspecto actual, siendo además una estructura que delimita la Gran Plaza y la separa del complejo arquitectónico conocido como Pequeña Acrópolis situado hacia el sureste (Figura 2).

De los monumentos de piedra cabe señalar, entre otros, la Estela 8, pues aunque fue erigida a comienzos del siglo vil d.C. por el gobernante Yuhkno'm Took' K’awiil, en su narrativa destaca la evocación de hechos dinásticos fundamentales fechados para los momentos finales del siglo vi d.C., cuando los gobernantes del glifo emblema de la Cabeza de Serpiente podrían no estar asentados aún en la entidad política campechana. En el sector B de la Estructura IV se halló un monumento pétreo conocido actualmente como Dintel de la Estructura IV-B, o antiguamente como la Estela 117 de Calakmul, en el cual, debido a sus características morfológicas e iconográficas, se centrará el análisis del presente escrito (Figura 3).

\section{La Estructura IV-B de Calakmul}

Esta construcción, de acuerdo con Carrasco (2003: 154), se conforma de dos niveles con dos escalinatas y dos cuartos centrales de posible estilo constructivo Río Bec. El del primer nivel presenta una sola crujía y una escalinata central que arranca desde la plaza, mientras que el segundo, con el que se alcanza la mayor elevación de la estructura, se configura mediante tres espacios arquitectónicos 


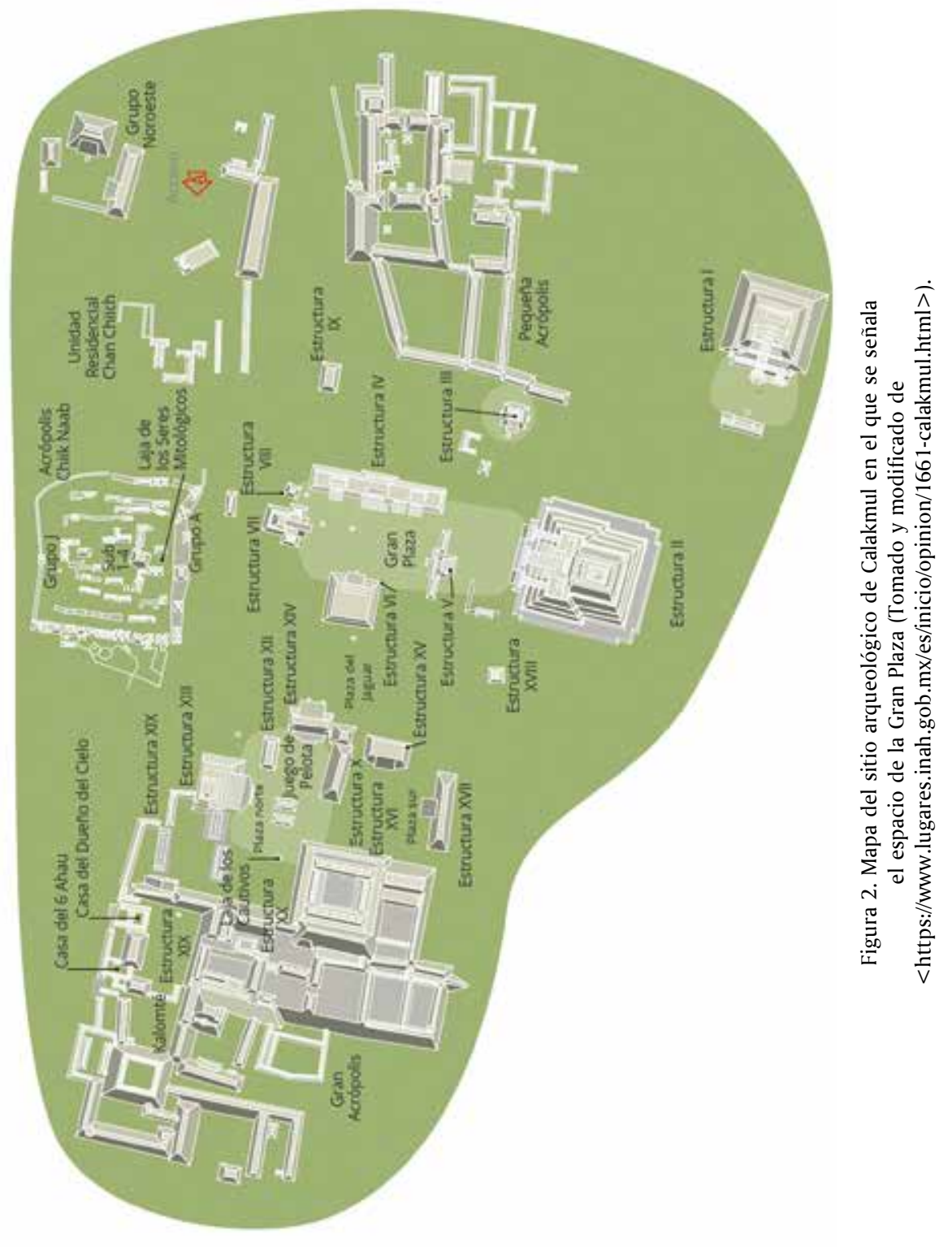




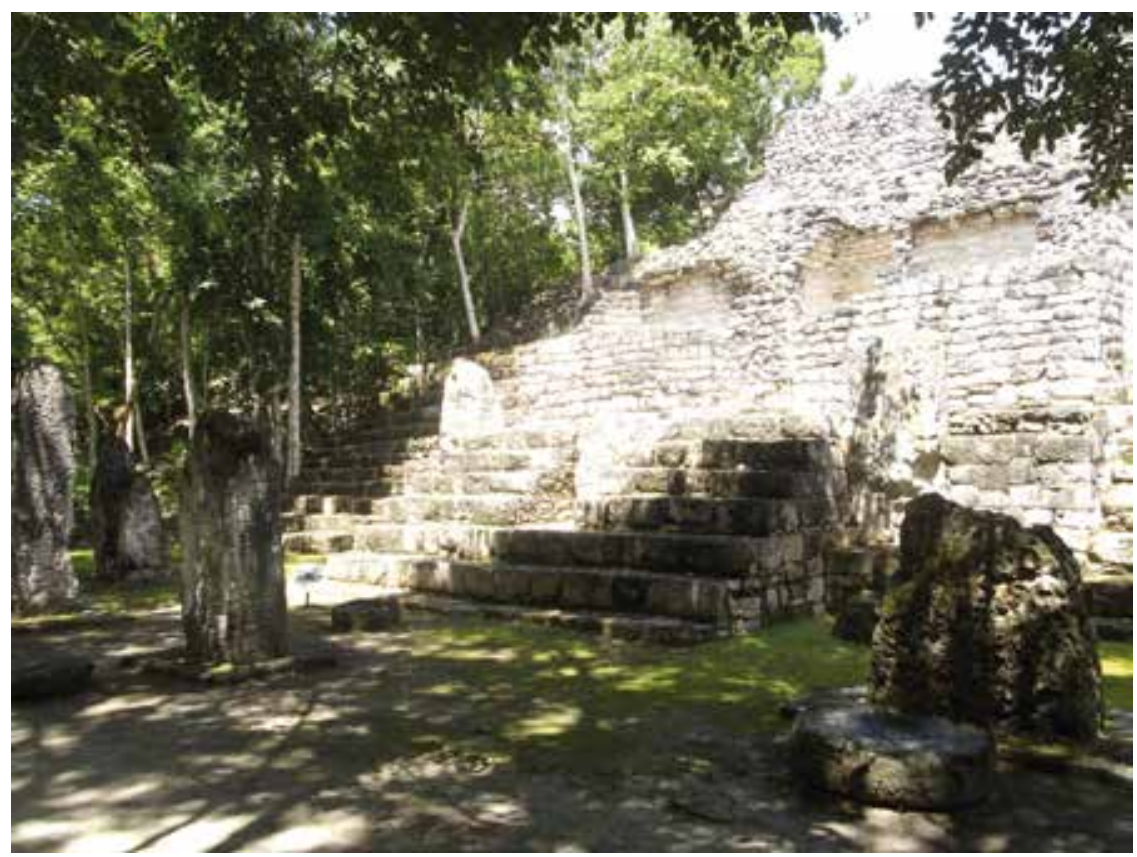

Figura 3. Estructura IV-B, Calakmul (Foto del autor).

(Figura 4). Estos espacios abovedados, con una altura aproximada de 2 metros, parecen haber estado recubiertos de estuco mientras que las fachadas se decoraban con diversa policromía registrada durante los trabajos arqueológicos (Nieves, Esparza y García, 1995: 102).

Durante los trabajos realizados en las escaleras laterales se recuperaron, fuera de su contexto arqueológico primario, varios escalones jeroglíficos (Nieves, Esparza y García, 1995), que forman parte del escaso corpus conocido para Calakmul junto con un bloque con una inscripción formada por 14 cartuchos tallados; éstos contienen una rueda calendárica que se refiere a un posible evento ritual de juego de pelota en el que estaban involucrados cautivos (Carrasco, 1999: 82). Asimismo, bajo el relleno de la escalera central se encontraron dos monumentos pétreos, un altar y una posible estela, misma que será la protagonista de este trabajo y se analizará a continuación.

Pero antes cabe señalar las dos tumbas registradas en el segundo nivel de la estructura, los dos enterramientos del primer nivel y el gran número de depósitos rituales, escondites o caches, ocho en total (Vázquez, 2014), compuestos por objetos cerámicos, vestigios humanos, jade, obsidiana y restos marinos (Carrasco, 1999) asociados tanto a las modificaciones estructurales como al levantamiento de estelas vinculadas a la Estructura IV-B (de la 9 a la 18 según los informes de Ruppert y Denison, 1943: 47). Gracias a las ofrendas cerámicas descubiertas se 


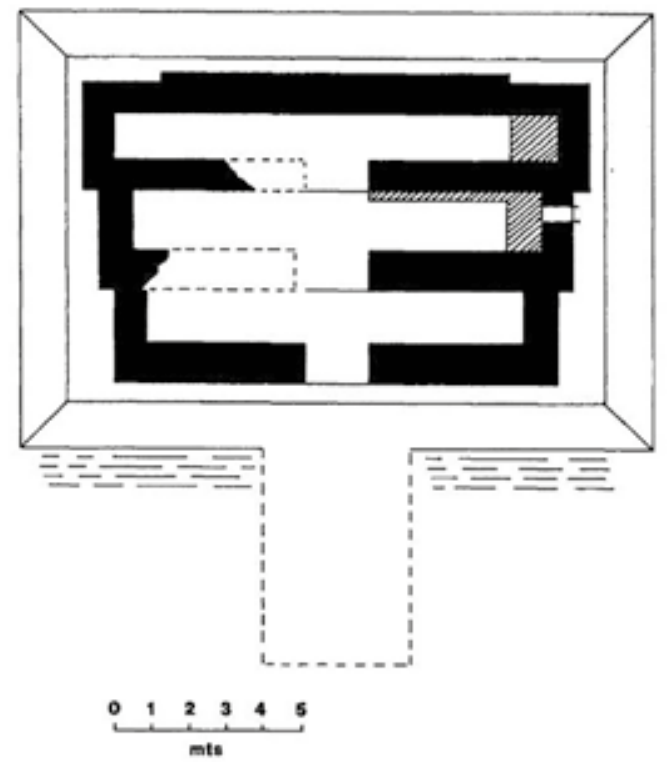

Figura 4. Planta del nivel superior de la Estructura IV-B (Tomado de Nieves, Esparza y García, 1995: 3b).

ha podido concluir que, además de la existencia de un edificio preclásico (Domínguez, 2008), el periodo de mayor actividad se constata durante el Clásico Temprano, cuando abunda la cerámica de tipos Águila Naranja y Balanza Negro.

Según Braswell y colegas, las remodelaciones sufridas por la estructura sirven "para conferirle otro significado a la misma pasando de complejo astronómico a monumento funerario para el gobernante temprano de Kaan llamado K'altuun Hix" (Braswell et al., 2004: 169), a quien pertenecería, según los investigadores, una de las tumbas encontradas en el basamento. Ésta es la conocida como Tumba 2, hallada en un nivel inferior a la Tumba 1 (Figura 5) y con indicios de haber sido "revisitada" por los antiguos habitantes de Calakmul; presentaba un importante ajuar funerario entre el que destaca una máscara de jade y objetos cerámicos del tipo Balanza Negro (Figura 6), que se ubican temporalmente en el Clásico Temprano. Además, el estudio de los restos humanos recuperados reveló la edad adulta del personaje enterrado; por ello, debido a la riqueza del ajuar, la temporalidad de los restos cerámicos y la longevidad del sujeto, los investigadores concluyeron que la Tumba 2 debía ser la "morada" del antiguo gobernante de la dinastía de la Cabeza de Serpiente, Tuun K’ab Hix (también conocido como K'altuun Hix o K'ab Tuun Hix) de quien sabemos, gracias a las referencias jeroglíficas de las que disponemos actualmente en sitios como Naranjo (Martin et al., 2016) o La Corona (Martin, 2008; Stuart et al., 2018), que estuvo al frente de la dinastía desde el 520 hasta el 546 d.C. 


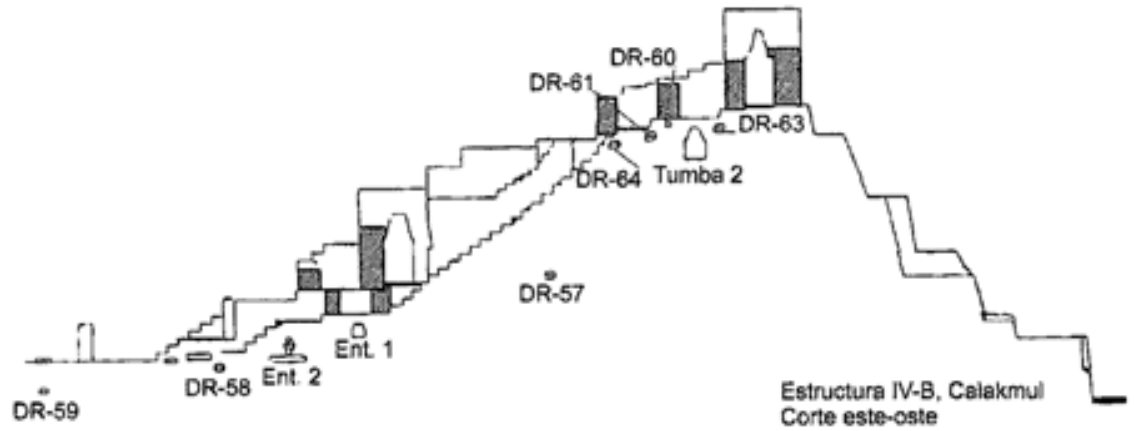

Figura 5. Corte de la Estructura IV-B de Calakmul

(Tomado de Carrasco, 1999: 72).

Sin embargo, no se encontró ningún registro jeroglífico que pudiera confirmar dicha aseveración como parte de la tumba del supuesto gobernante, y la identificación se realizó a través de la aproximación cronológica por el ajuar cerámico que acompañaba al personaje y, además, por el hallazgo de un altar y un monumento pétreo (catalogado en un primer momento como estela) que formaban parte del relleno de la escalera central y que los arqueólogos relacionaron con la Tumba 2.

\section{Análisis de la Estela 117 o Dintel de la Estructura IV-B}

La Estela 117 o Dintel de la Estructura IV-B de Calakmul (Figura 7), es un monumento que mide aproximadamente 1.97 metros de alto desde su base actual (la parte superior se encuentra fracturada), ${ }^{1}$ por $91 \mathrm{~cm}$ de ancho y un grosor de 18 $\mathrm{cm}$ en su parte más ancha; en la que pudiera ser su cara frontal se representa a un posible gobernante sentado en un trono, portando armamento militar y pisando una montaña sagrada con hendidura central y referencia toponímica. Destaca la presencia de varios cartuchos jeroglíficos que, lamentablemente, parecen no haber sido labrados, por lo que se puede valorar como un monumento inacabado. Teniendo en cuenta que no es el único ejemplo de este tipo conocido dentro del corpus de monumentos, cabe señalar que su aspecto quizás se deba al hecho de que en su proceso de elaboración participaban diversos especialistas, por ello, aunque la representación iconográfica parece haberse finalizado, los espacios en los que debían insertarse los signos jeroglíficos nunca fueron esculpidos, pues esta labor correspondería a escultores especializados en la escritura (Pérez Suárez, 2000: 67).

\footnotetext{
${ }^{1}$ Analizando el monumento de manera vertical al tomar como referencia el registro iconográfico.
} 


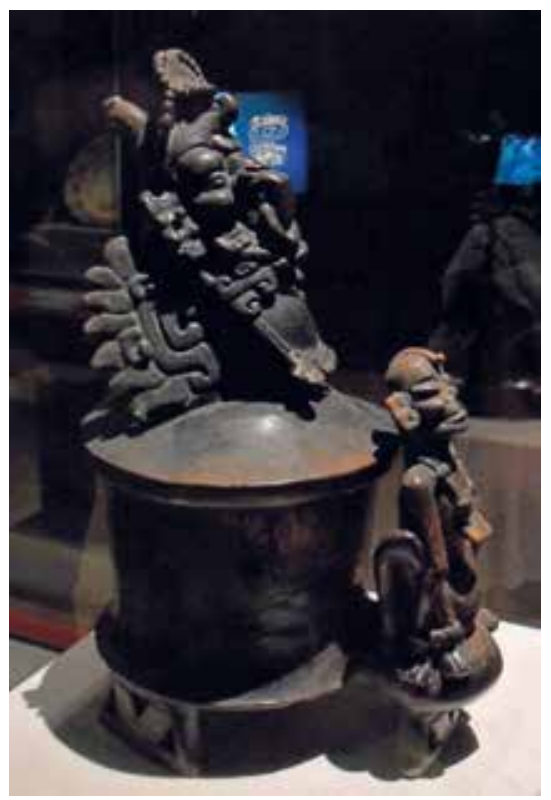

Figura 6. Vasija trípode con la deidad Pájaro Principal y un mono araña. Tumba 2, Estructura IV-B, Calakmul (Foto del autor).

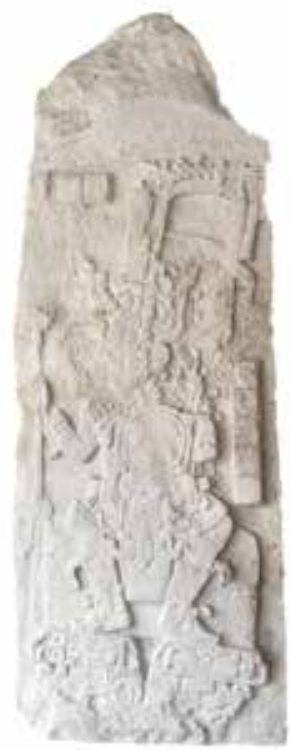

Figura 7. Estela 117 o Dintel de la Estructura IV-B de Calakmul (Foto del autor). 
En un primer momento se consideró que el monumento pétreo formaba parte de una subestructura anterior, y por ello Carrasco y Boucher afirmaron que "[...] lo que se pensó en un principio era una estela [...] Después de un análisis detallado tanto del área esculpida como del conjunto de la pieza se pudo comprobar que corresponde a un dintel [...]" (Carrasco y Boucher, 1994: 35). Un dintel que, junto a un altar circular, habría formado parte del relleno constructivo de la escalinata central de la Estructura IV-B (Carrasco y Boucher, 1994) durante su última remodelación en el Clásico Tardío, y ambos podrían haber sido "quizá matados ritualmente y enterrados en una ceremonia para la colocación de las Estelas 10, 11 y 12" (Carrasco, 1999: 82). Cabe destacar que el altar conserva signos grabados que parecen representar una flor y elementos tipo pop o 'estera/petate' (Figura 8), que todavía se pueden discernir en la actualidad; ${ }^{2}$ estos últimos están muy relacionados con el ejercicio del poder al encontrarse representaciones iconográficas que vinculan las esteras con los tronos en los que se sentaban los gobernantes dinásticos (Florescano, 2009).

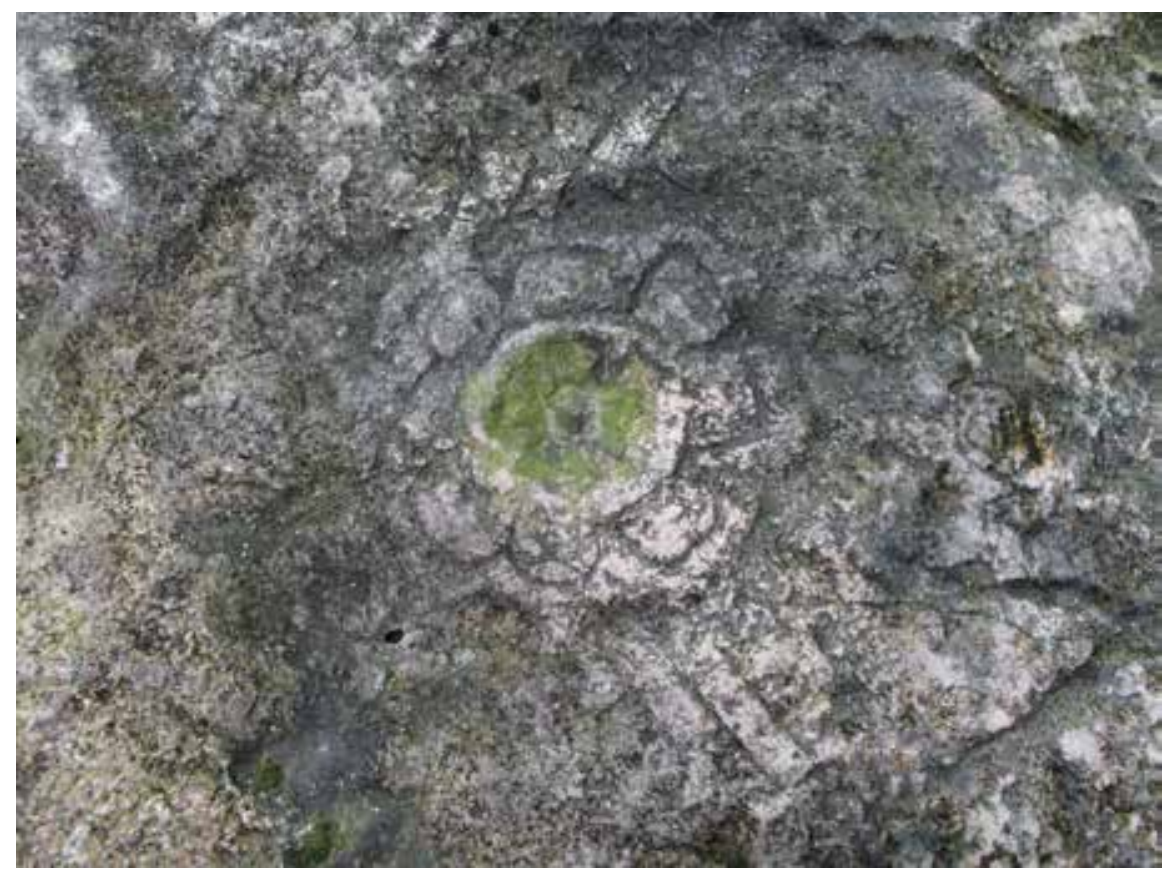

Figura 8. Signos del altar circular de la Estructura IV-B, Calakmul (Foto del autor).

\footnotetext{
${ }^{2}$ Debo señalar que Nieves y colegas apuntaron también la presencia de "un pequeño cefalomorfo de aspecto glífico” (Nieves, Esparza y García, 1995: 104), el cual me ha sido imposible identificar tras una observación del monumento in situ.
} 
A pesar de la clasificación tipológica realizada por Carrasco y Boucher, el monumento fue referido como Estela 117 de Calakmul por Martin, tal y como se puede observar en la descripción que realiza en su informe epigráfico de la temporada de trabajo del Proyecto Arqueológico Calakmul ${ }^{3}$ de los años 1997 y 1998 (Carrasco, 1998). Asimismo, Nieves y colegas siguiendo registros previos (Marcus, 1987) también se refieren a ella como estela y le asignan una catalogación, “estela 114" [sic] (Nieves, Esparza y García, 1995: 104), hoy en día desechada pues nada tiene que ver con la conocida como Estela 114 de Calakmul que se encontró en el lado norte de la Estructura II. ${ }^{4}$ En este sentido, la clasificación del monumento como dintel, "ejecutado en el más puro estilo Petén" (Carrasco, 1999: 82), lo convertía en uno de los escasos ejemplos de este tipo conocidos para la zona petenera y favorecía su ubicación temporal al relacionarlo, por una parte, con los objetos cerámicos encontrados en la estructura y, por otra, con los dinteles de la entidad política de Yaxchilán (situada a las orillas del río Usumacinta en el actual estado mexicano de Chiapas), donde el Dintel 35 se refiere, en los cartuchos jeroglíficos C5-D8, a la captura y posible sacrificio ritual de un yajawte' del gobernante temprano de Kaan Tuun K'ab Hix el 14 de enero del año 537 d.C. (Bernal, 2014).

\section{Cronología}

Durante los trabajos arqueológicos desarrollados en la Estructura VII de Calakmul en el año 2000, el pac reportó el descubrimiento de un dintel de piedra (catalogado como Dintel 2) en el desplante de la escalera central en una subestructura con representación iconográfica femenina y restos de cartuchos jeroglíficos (Carrasco, 2000: 59). García Barrios y Vázquez (2011: 64) sugieren que, teniendo en cuenta la actividad ritual de esparcimiento de incienso que parece estar realizando la mujer representada y su tipo de vestimenta, el monumento podría relacionarse con la Estela 116 de Calakmul que conmemora el final del k'atun 13, es decir, una fecha cercana al 692 d.C. Lo anterior debido a que, siguiendo a Vázquez, "durante el Clásico Tardío las mujeres adquieren una mayor importancia en los programas monumentales públicos jugando un rol substancial en la política del reino de Kanu'l" (Vázquez López, 2017: 21; la traducción es mía), al estar dichos rituales muy vinculados a las celebraciones de fines de periodo.

Teniendo en cuenta lo anterior, se debe señalar que el monumento de la Estructura IV-B fue hallado en el relleno constructivo de la escalera central cuya última modificación estructural se llevó a cabo, según Carrasco, durante el Clásico Tardío; ello coincide con las fechas registradas en las estelas conservadas al

\footnotetext{
${ }^{3}$ En lo sucesivo me referiré a él por las siglas PAC.

${ }^{4}$ Quizá esta confusión resida en el hecho de que Marcus, en su obra de 1987, cataloga un total de 113 monumentos de Calakmul, ya que no será hasta 1994 cuando se descubra la conocida actualmente como Estela 114 (Marcus, 2001: 37).
} 
frente de la estructura que narran hechos ocurridos entre el 642 y 810 d.C. En este sentido, es significativo que las Estelas 10,11 y 12 (monumentos que según Carrasco podrían haber estado involucrados en el ritual que implicó la fractura y ofrenda del Dintel de la Estructura IV-B) formen parte de un contexto cronológico fechado para el Clásico Tardío. Sin embargo, lo anterior contradice la hipótesis de la supuesta temporalidad temprana del monumento y, por ende, que el personaje representado (y enterrado en la Tumba 2) fuese el gobernante temprano de Kaan, Tuun K'ab Hix.

Para reforzar la supuesta temporalidad temprana del monumento, Carrasco apunta que:

en las escalinatas que dan acceso al segundo nivel fueron localizados cuatro bloques, cada uno de ellos con inscripciones glíficas [...] el bloque del segundo peldaño de la escalinata norte hace referencia a la fecha de nacimiento de un personaje; la fecha en rueda calendárica correspondería a 7 Ik 10 Ceh (Carrasco, 1999: 83).

Efectivamente, la Rueda Calendárica $7 i k^{\prime} 10 \mathrm{kej}$, usando la constante de correlación 584283, permite reconstruir varias fechas de nacimiento que caerían en el Clásico Temprano y que se ajustarían a la posible temporalidad del gobernante dinástico. Sin embargo, no hay que olvidar que, por una parte, estos peldaños fueron reutilizados y no se encontraron en su contextos originales y, por otra, que los recientes descubrimientos que se han realizado en los sitios de Xunantunich en Belice (Helmke y Awe, 2016) y La Corona en Guatemala (Stuart, 2012), han revelado que los gobernantes de Kaan no se asentaron en Calakmul hasta comienzos del siglo vil d.C., sino que las referencias jeroglíficas más tempranas que se conocen hasta la fecha se ubican en la región sur de Quintana Roo, siendo Dzibanché la entidad política que podría haber fungido como capital dinástica durante dicho contexto (Nalda et al., 2004).

Asimismo, el estudio iconográfico del monumento aporta otros datos cronológicos ya que estilísticamente la figura representada puede encuadrarse dentro de las conocidas como "Fase Ornamental" y "Fase Dinámica" (Proskouriakoff, 1950), las cuales abarcarían un periodo comprendido entre el final del siglo VII y comienzos del siglo ix d.C., y se caracterizan por el desarrollo ornamental. En este sentido, la representación del personaje no corresponde con la posición típica que se observa en los monumentos pétreos del Clásico Temprano, de perfil hierático, con las piernas y los pies apuntando a la misma dirección y en muchas ocasiones portando la barra ceremonial como símbolo de autoridad, sino que la figura se dispone de frente, sentada en un trono, con las piernas flexionadas y las puntas de los pies sobre la montaña partida, lo que le concede una mayor expresión a toda la composición (Figura 9). 


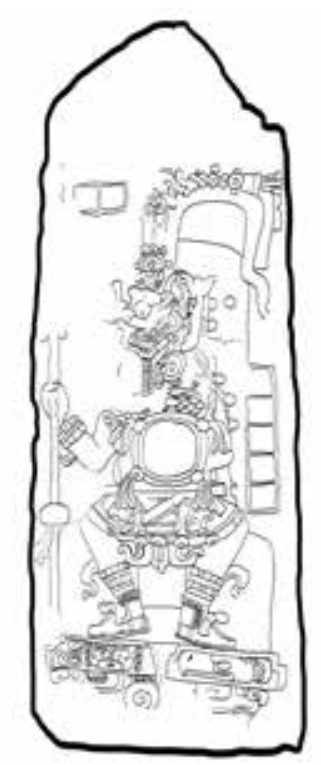

Figura 9. Dibujo de la Estela 117 o Dintel de la Estructura IV-B de Calakmul (Dibujo del autor).

Hasta donde se ha podido indagar, sólo se cuenta con otro monumento pétreo ${ }^{5}$ en el que se representa a un gobernante en tal posición, la Estela 2 de Cancuén (Figura 10). Fechada para finales del siglo vilI d.C., representa al gobernante Taj Chan Ahk sentado sobre un trono y posando las puntas de sus pies sobre un cautivo (Fahsen y Demarest, 2001).

El análisis iconográfico detallado que se presenta a continuación sirve también para obtener una aproximación cronológica más exacta del monumento pues, por ejemplo, el estudio de las sandalias (y los elementos decorativos por encima de los tobillos) permite determinar que por sus características forman parte de las representaciones típicas del Clásico Tardío (Proskouriakoff, 1950: 86), con una tobillera prominente con decoración posiblemente textil, y el talón reforzado y de una sola pieza.

Iconografía. El mascarón central

Como se apuntó, la representación iconográfica del monumento es atípica (pues lo normal es que los gobernantes se encuentren de pie o sentados con las piernas cruzadas o apoyadas sobre la montaña), por eso las primeras interpretaciones

${ }^{5}$ En el Dintel 1 del Templo IV de Tikal, monumento tallado en madera, la imagen central representa al gobernante Yihk'in Chan K'awiil (s. vil d.C.) sentado en un trono con la misma postura de pies que los representados en Cancuén y Calakmul; además porta objetos bélicos semejantes (lanza larga y rodela). 


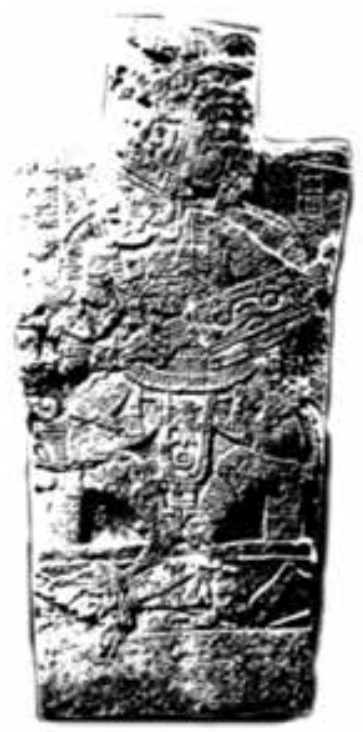

Figura 10. Estela 2 de Cancuén (Según Fahsen y Demarest, 2001: 869).

consideraron que la flexión de las piernas y pies del personaje indicaban la conmemoración de un evento que implicaba una danza ritual (Carrasco y Boucher, 1994: 36). Sin embargo, al igual que en la Estela 2 de Cancuén, el personaje se encuentra sentado sobre un amplio trono y reposa sus pies sobre una montaña partida por una marcada hendidura central. Recientemente, García ha propuesto que la asociación entre el gobernante y la montaña, considerada sagrada, ${ }^{6}$ se debe a la búsqueda de legitimación de su autoridad pues "en él se concentraban las ideas de territorio, fertilidad, riqueza y culto a los ancestros que le permitieron ejercer el poder político" (García Capistrán, 2019: 141). ${ }^{7}$ Teniendo esto en cuenta, se puede aseverar que el personaje representado era entonces un gobernante que proclamaba su autoridad de manera simbólica al asociarse con la montaña, un lugar sobrenatural que además de contener abundancia de alimento y bebida, en él residían ciertas deidades y antepasados.

En el caso del monumento analizado, la hendidura central de la montaña parece estar originando la aparición de dos entidades witz, dos mascarones diferenciados por los rasgos iconográficos que los componen y por los cartuchos jeroglíficos que se encuentran en su parte superior (Figura 11). Sin embargo, existen otros ejemplos en los que los mascarones pueden parecer incluso tripartitos, con

${ }^{6}$ Ha propuesto también que el origen del concepto podría rastrearse hasta tiempos olmecas, siendo la hendidura en $\mathrm{V}$ de las figurillas "el antecedente de la hendidura escalonada de las representaciones de montañas mayas en el periodo Clásico” (García Capistrán, 2017: 67).

7 Sería lo que anteriormente Taube había identificado como "Montaña Florida” (Taube, 2004). 
un elemento frontal y dos laterales, siendo en realidad una única entidad cuyo nombre se registra en las oquedades oculares. En el caso del witz del Tablero de la Cruz Foliada de Palenque, los signos inscritos en sus ojos componen su nombre; siguiendo a Bernal (2012: 230), éste sería Yax Haal Witz Nal, "la montaña del maíz de la nueva creación"; por ello, parado encima de la hendidura central y de las hojas del maíz que salen de ella, se encuentra K'inich Kan Bahlam, el heredero y nuevo gobernante de Palenque. Además, este lugar sobrenatural tuvo una gran importancia en la mitología palencana ya que en él nacería la deidad Unen K'awiil.

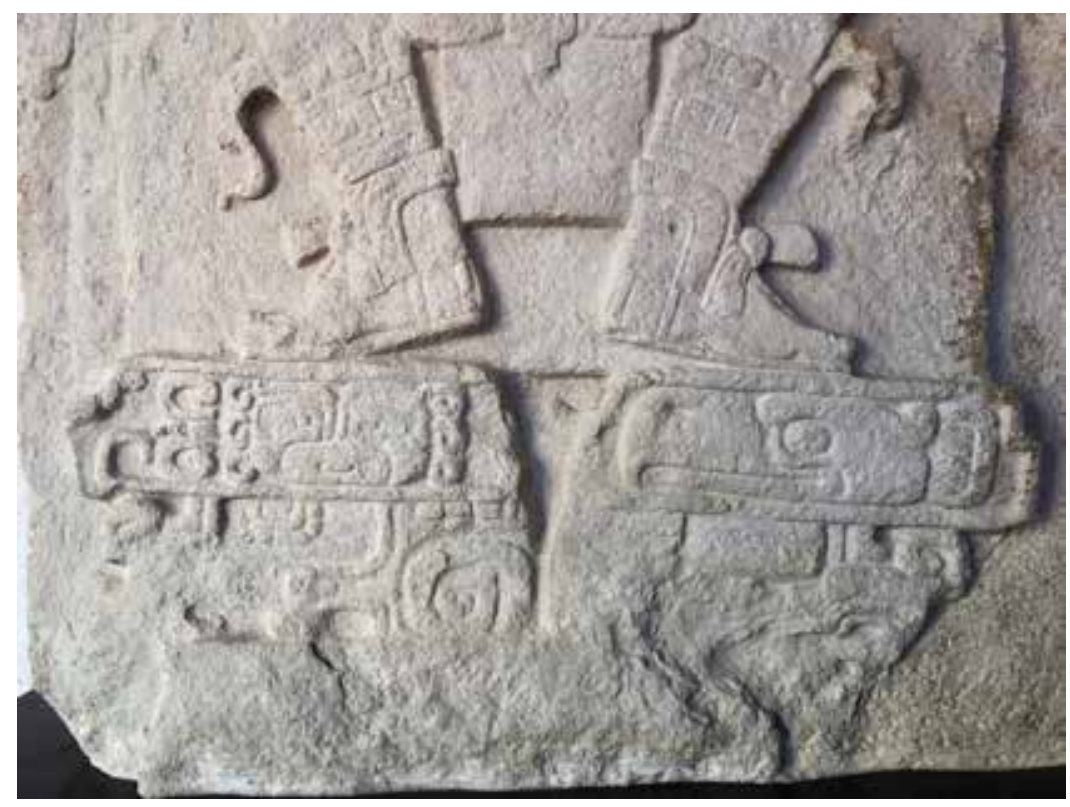

Figura 11. Parte inferior del Dintel de la Estructura IV-B de Calakmul o Estela 117 (Foto del autor).

Con base en lo anterior, cabe la posibilidad de que el witz sobre el que posa sus pies el gobernante del monumento de Calakmul sea un único ser (con elementos TUN y KAWAK característicos), cuyo nombre se compone de cuatro posibles sílabas: ya-xo (en la parte izquierda) y ?-ka (en la derecha). Además, hay que señalar que en Copán, Honduras, la Estructura 10L-22a, conocida como Popol Nah o "casa del consejo" (Figura 12), fechada para el Clásico Tardío, presenta en su fachada lo que han sido considerados como nueve topónimos mitológicos (Stuart y Houston, 1994) sobre los que se sentaban nueve personajes; entre los signos destaca el mismo que aparece en el monumento calakmuleño, lo que refuerza la idea de que todo el conjunto iconográfico de la montaña partida representada de manera bicéfala, se refiera a un único lugar. 


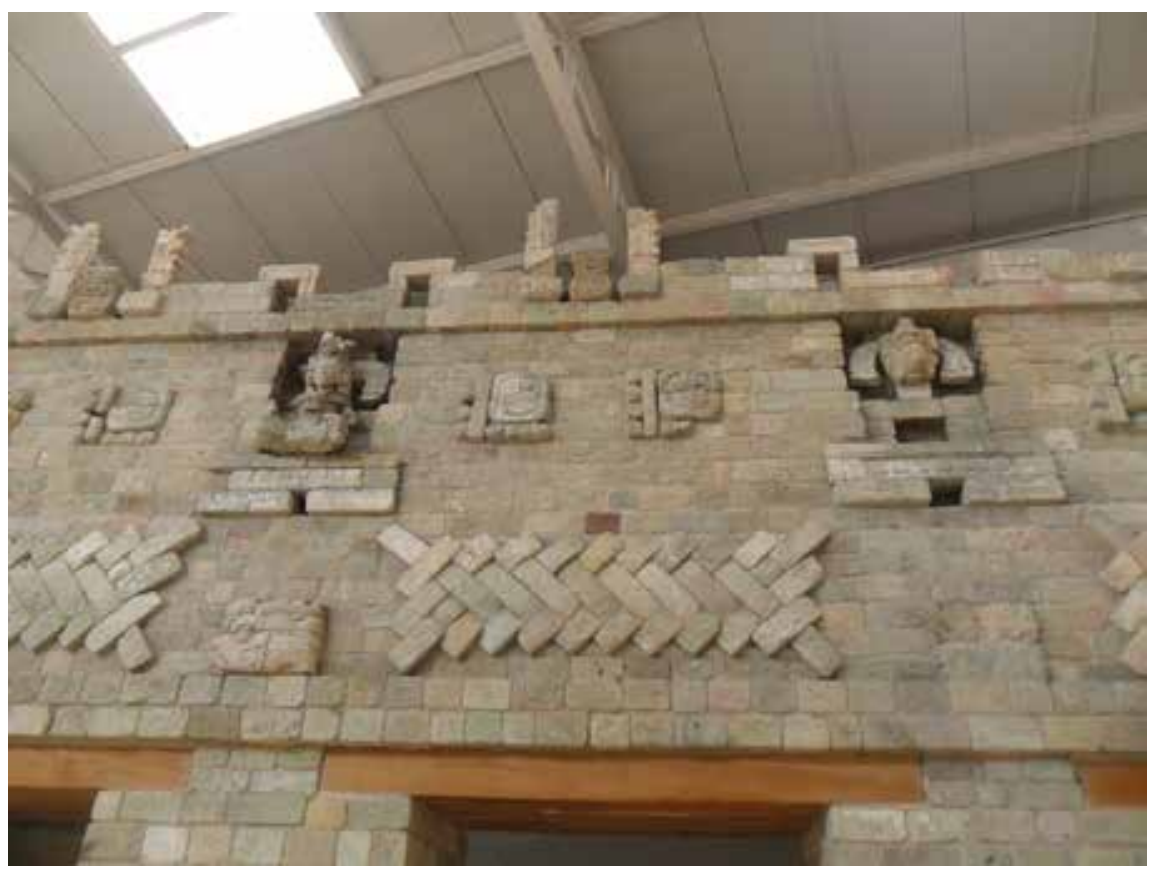

Figura 12. Reconstrucción de la fachada de la Estructura 10L-22a. Museo de sitio de Copán (Foto del autor).

Wagner (1998: 32), siguiendo las hipótesis de Fash, consideró que podrían estar representando localidades sobrenaturales asociadas a linajes particulares o referirse a ciertos linajes con características sobrenaturales. En este sentido, lo cierto es que en otros monumentos de Copán (por ejemplo en la Estela 10) se vuelven a nombrar algunos de los lugares mitológicos referidos en la fachada de la estructura, como Ik' Wahy Nal e Ik' Nahb Nal; sin embargo, del topónimo que aparece también en Calakmul no se conocen más alusiones. Schele, Stuart y Grube transliteraron los signos como ya-xo-o-ka, los transcribieron como ya xo'ok/yax ok, y lo tradujeron como 'primera pierna' o 'primer pie' (Schele, Stuart y Grube, 1991: 4), sugiriendo que se refería a eventos de fundación. Sin embargo, en el presente análisis se considera que el tercer signo, aquel que parece representar una cabeza aviar, no tiene todavía una lectura exacta, ya que la sílaba ka, siendo un complemento, pudiera indicar su valor de logograma y no de fonema, lo que dificulta su interpretación (por ello, en las siguientes páginas será transliterado con interrogante). Además, por el mal estado de conservación de la escultura de Copán que acompaña al nombre toponímico (Figura 13), no se puede realizar un análisis iconográfico que permita conocer más sobre la identidad del personaje. 


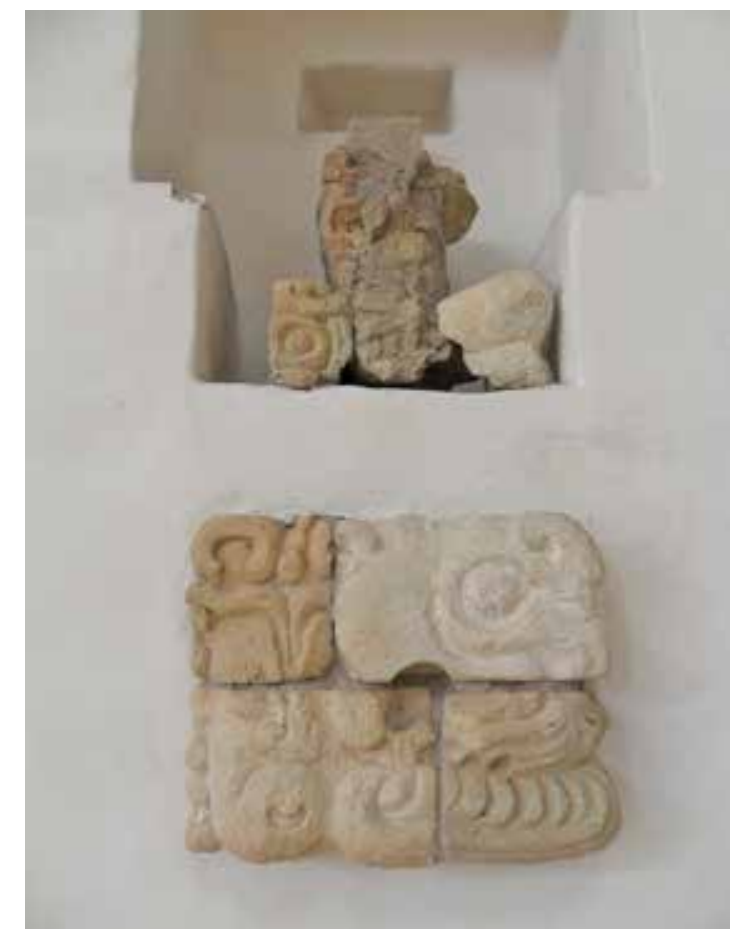

Figura 13. Personaje y posible nombre toponímico ya-xo-?-ka de la Estructura 10L-22a de Copán (Foto del autor).

En cuanto a la función de la estructura copaneca, es interesante señalar lo que indicó Wagner, quien le otorgó una función relacionada con el culto a los muertos y la veneración a los ancestros (Wagner, 1998: 43), siendo los nueve personajes representados los nueve señores del inframundo que "personifican las fuerzas naturales que garantizan la abundancia agricultora y así la subsistencia de los humanos" (Wagner, 2005: 40).

En este sentido, la posición de la figura del monumento de Calakmul podría indicar que, aunque sentado sobre el trono, el gobernante emerge de la hendidura de la montaña personificando al dios del maíz. Esta encarnación simbólica se vincula con el mito conocido del Bebé Jaguar, el cual fue muy representado en las vasijas tipo códice del periodo Clásico Tardío; en éste, el Bebé Jaguar, que renacerá como el dios del maíz, es lanzado a una montaña sagrada con hendidura central y la acción es contemplada y desarrollada por personajes sobrenaturales relacionados con la muerte, entre otros seres (García Barrios y Carrasco, 2006). Según García Capistrán y Valencia (2017: 404), la hendidura central es un lugar sobrenatural llamado Pa'axiil, aquel de donde proviene el maíz, por ello, tras ser arrojado en dicha localidad, el mito exhibe el renacimiento de la deidad en todo 
su esplendor. Cabe señalar que los mitos del Bebé Jaguar y el nacimiento del dios del maíz fueron representados en variados objetos cerámicos encontrados en Calakmul cuya cronología se encuadra en el Clásico Tardío (García Barrios, 2011).

Quizá por ello en el monumento de la ciudad campechana se pueden observar pequeñas foliaciones que salen tanto de las muñequeras como de las ajorcas superiores que viste el personaje; en una de ellas, se distingue todavía un pequeño elemento circular que podría estar representando los granos de maíz (como en la Estela 1 de Bonampak). Asimismo, en la parte superior del tocado del gobernante destaca un pequeño mascarón zoomorfo del que brota un elemento vegetal con tres signos circulares simbolizando quizá la fertilidad de la deidad encarnada (y de la que, por ende, toma sus cualidades). Por último, cayendo de su faldellín se puede observar un elemento trilobular que, más allá de su aspecto decorativo, podría estar reforzando el concepto del gobernante como personificación de la deidad del maíz.

Cabe advertir que en la Estela 53 de Calakmul (Figura 14), monumento erigido por el gobernante Yuhkno'm Took' K'awiil durante la celebración de un final de k'atun 9.15.0.0.0 (es decir, en el año 731 d.C.), se representa al ajaw de pie frente a un cautivo. Para el presente estudio, destaca la identificación de los mismos elementos vegetales que se analizaban anteriormente tanto en las ajorcas como en las muñequeras; además, en la parte inferior de un gran cinturón con representación antropomorfa se dispone un elemento trilobular que cuelga hasta la altura de sus rodillas.

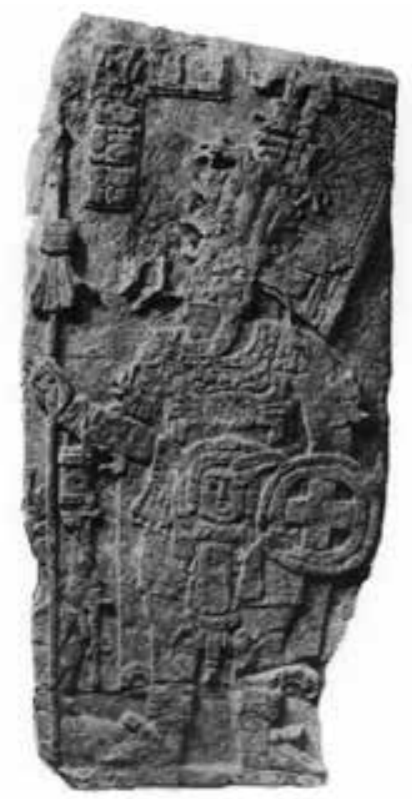

Figura 14. Estela 53 de Calakmul (Según Pallán, 2006: 3.1.g). 
Los elementos vegetales que se presentaron anteriormente no son las únicas similitudes iconográficas que se pueden encontrar entre el monumento de la Estructura IV-B y la Estela 53 de Calakmul. Por ejemplo, las sandalias que viste el gobernante en la estela corresponden al mismo tipo que las representadas en el monumento de la IV-B, con una especie de nudo en el empeine como elemento de sujeción y decoración.

Asimismo, en ambos retratos el gobernante porta elementos bélicos, un pequeño escudo circular y una lanza larga que, en los dos casos, se decora con plumería. En cuanto a la rodela del monumento de la IV-B, agarrada con su mano izquierda se alza hacia el pecho, lo que cubre toda la decoración central de la vestimenta del personaje. Tradicionalmente en la parte central del objeto marcial suele representarse en muchas ocasiones al dios Jaguar del Inframundo al estar muy relacionado con el aspecto bélico (Valverde, 2004), pero en esta ocasión y debido al desgaste de la pieza se carece de elementos que permitan realizar una interpretación fidedigna. Sin embargo, en la Estela 53 de Calakmul el ajaw carga en su mano izquierda un pequeño escudo decorado en cuya parte central es claramente legible un signo de quincunce o cruz k'an; además, tanto en la parte superior como inferior se disponen dos elementos decorativos de plumería similares a los que se pueden reconocer en el escudo del monumento de la IV-B, un componente iconográfico fechado también para el Clásico Tardío (Proskouriakoff, 1950: 92).

El faldellín que viste el personaje sentado destaca por la presencia de dos elementos que remiten al inframundo y que forman parte de la decoración de la prenda, huesos cruzados y globos oculares (Figura 15). Dentro del panteón maya prehispánico, entre las deidades que portaban estos rasgos se encuentra la conocida como Ahkan, que tenía diferentes manifestaciones (Grube, 2004); una de ellas, de nombre Jatz'no'n Ahkan, formaba parte de las entidades anímicas o wahyis vinculadas a los gobernantes sagrados de la dinastía Kaan durante el Clásico Tardío, tal y como aparece referido en la vasija cerámica K791. Por lo anterior, pudiera ser que a través del programa iconográfico del vestuario del gobernante se estuviese haciendo referencia también al ajaw como la personificación terrenal de dicha entidad sobrenatural.

Continuando con el vestuario, debido a la posición de la rodela, el artista que realizó la composición no representó el gran collar del señor (elemento iconográfico tradicional en otros monumentos contemporáneos), sin embargo, sí se puede observar un peto que le cubre los hombros. Éste, compuesto por cuentas circulares, posiblemente de jade, también fue muy bien representado, por ejemplo, en la Estela 35 de Calakmul y quizá tuvo una apariencia similar a la del hallado en el ajuar de la Tumba 1 de la Estructura VII de Calakmul (Figura 16). 


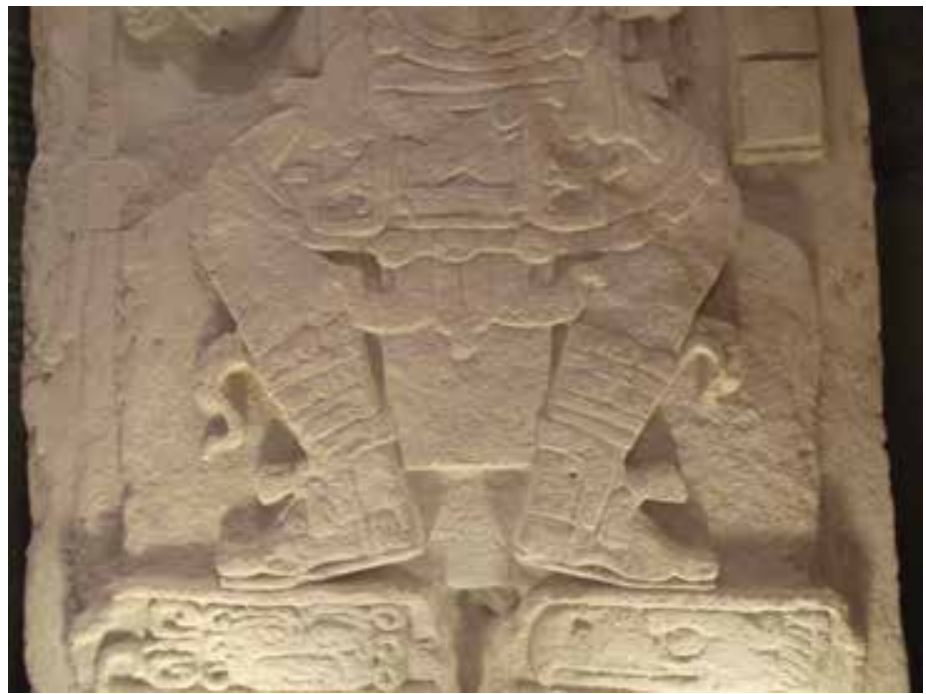

Figura 15. Parte inferior del monumento de la Estructura IV-B de Calakmul (Foto del autor).

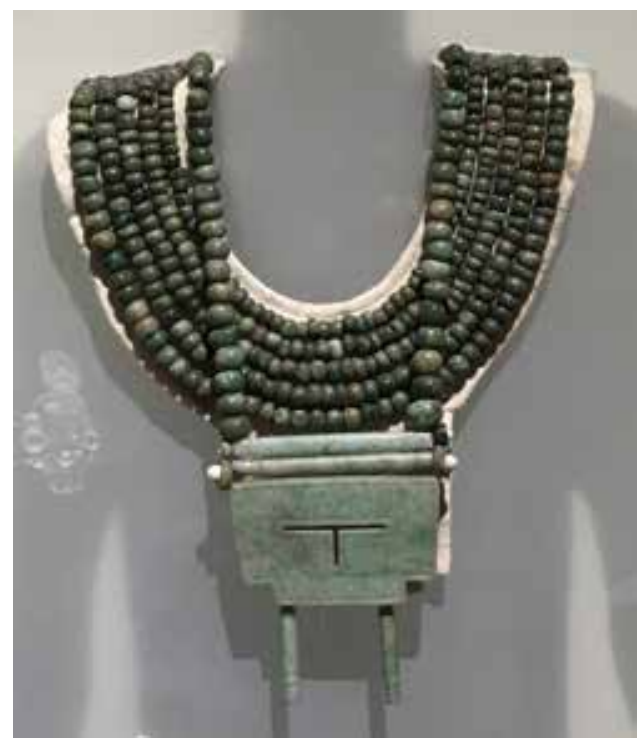

Figura 16. Peto y collar de jade con signo $i k$ ' encontrados en la Tumba 1 de la Estructura VII de Calakmul (Foto del autor).

En cuanto a la decoración del yelmo y el tocado que viste el gobernante del monumento de la Estructura IV-B (Figura 17), se pueden identificar las teselas tu- 
bulares y cuentas, posiblemente de jade, que podrían formar parte de un ko'haw, un símbolo de autoridad militar que servía como base para toda la parafernalia de la que se componía el tocado (Nielsen y Helmke, 2011: 348). En otras estelas conocidas de Calakmul, como la 52 del Clásico Tardío o la temprana 114, los representados parecen portar dicho casco bajo su tocado (Velásquez y Pallán, 2006); durante el periodo Clásico, el ko'haw se convirtió en un elemento recurrente en la iconografía de los gobernantes, como puede observarse en otras entidades políticas de las Tierras Bajas mayas como el Panel 2 de Piedras Negras, entre otros. Tras el yelmo, se reconoce un arreglo en forma de pop, "estera" o "petate" de seis nudos que parece servir como soporte para una parte trasera en la que se distinguen dos cabezas de ofidios sobrenaturales y un elemento circular, quizá una orejera.

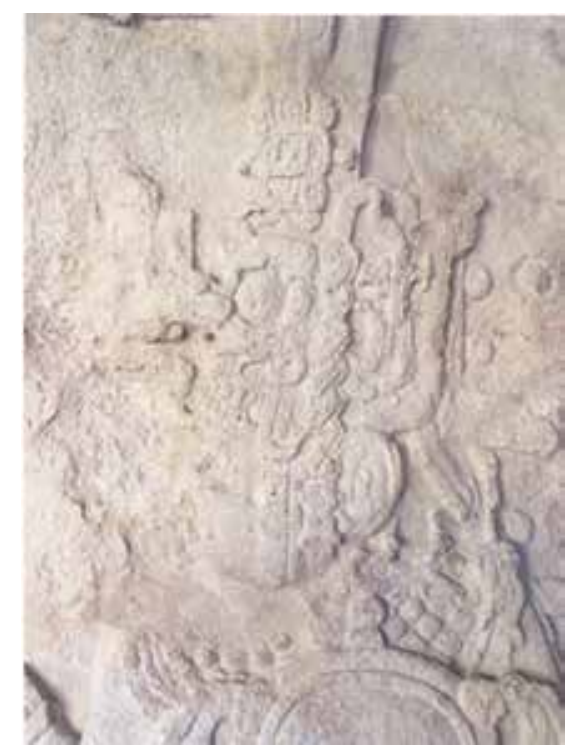

Figura 17. Sección central del tocado del gobernante del monumento de la Estructura IV-B de Calakmul (Foto del autor).

La serpiente de la parte superior se caracteriza por el elemento supraorbital en forma de "u", un largo hocico que apunta hacia arriba y una serie de colmillos sobresalientes, mientras que la que emerge de la parte inferior del componente circular, aunque también tiene los mismos elementos supra orbitales y colmillos, su largo hocico termina hacia abajo. Estos ofidios sobrenaturales, como parte del atuendo del gobernante, son entidades que acompañan a los k'uhul ajawtaak de otras dinastías del Clásico que pueden reconocerse en los complejos iconográficos de Quiriguá (Estela J), Xultún (Estela 10), Nim Li Punit (Estela 2) o en la misma Estela 51 de Calakmul, entre otros. 
En el mascarón central del tocado se puede apreciar la representación de un ser zoomorfo con un hocico que se pierde debido al desgaste del monumento, lo que parecen pequeños colmillos ganchudos, un elemento supraocular ondulado y una vírgula central en el ojo. Cabe señalar que encima de esta figura se sitúa una pequeña cabeza sobrenatural con un signo silábico to, que también podría estar funcionando como logograma e incluso como marcador nominal del ente representado. La idea anterior deriva de la representación iconográfica de la Estela 9 de Calakmul (Figura 18), misma que se ubicó en la fachada de la Estructura IV del sitio y que fue fechada para el 672 d.C. En ella se nombra al futuro gobernante Yuhkno'm Yihch'aak K'ahk' y muestra a un hombre y una mujer en la parte delantera y trasera del monumento. Cabe destacar que en el tocado que porta el personaje de la parte delantera se figuró a la misma entidad sobrenatural pero de su parte superior salen dos elementos ondulados con pequeños círculos punteados que corresponden al símbolo sencillo de la sílaba to. Asimismo, en la parte trasera de este gran ser sobrenatural se puede identificar al mismo ofidio que aparece en el tocado del gobernante de la Estructura IV-B, por ello se puede inferir que se trata del mismo ente y pudiera ser que formase parte del grupo de entidades patronas de los gobernantes dinásticos de Kaan. Pero se debe advertir que la representación de una entidad similar se encuentra en la Estela 6 de Naranjo (fechada para el 755 d.C.); en ésta el ajaw porta un tocado con características semejantes a los que visten los gobernantes de Calakmul, y el ser zoomorfo ha sido interpretado, recientemente, como la representación del dios de la lluvia (Beliaev, Vepretskii y Galeev, 2017: 61).

En esta ocasión, a diferencia de otros monumentos de Calakmul (Estela 52, Estela 53, entre otros) el tocado no presenta plumería, sino que en su parte superior, tras el posible elemento iconográfico vegetal, vuelve a aparecer una pequeña cabeza de rasgos serpentinos de la que surge un signo de petate de tres nudos culminado por un elemento decorativo similar al que aparece en el tocado de la Estela 9. Paralela a él se distingue una larga banda que cae hacia el lado izquierdo del gobernante; ésta podría coincidir con los motivos iconográficos representados en los monumentos de otras entidades políticas (como la Estela 2 de Ixlú o los Dinteles 3 y 14 de Yaxchilán), con la salvedad de que en el calakmuleño no son apreciables, posiblemente por el desgaste, los elementos achurados de su interior.

\section{Consideraciones finales}

El análisis del monumento pétreo de la Estructura IV-B de Calakmul permite identificar una iconografía tradicional en la que el personaje central adquiere un estatus superior al presentarse como la encarnación terrenal de la deidad del maíz que emerge de la apertura de la montaña sagrada, aquella en la que residen entidades patronas y deidades. Sin embargo, la posición del gobernante es atípica, al 


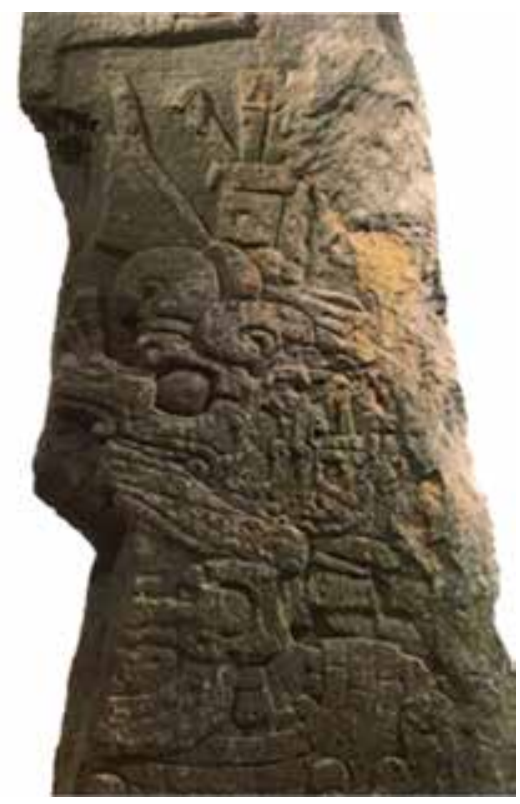

Figura 18. Parte superior de la Estela 9 de Calakmul (Foto del autor).

encontrarse sentado en su trono, reposando sus pies sobre la montaña; simbólicamente, al ubicarse sobre el lugar mitológico, el gobernante también legitima su autoridad al detentar la abundancia de bienes necesarios para el mantenimiento de su señorío. La presencia en su tocado de otras poderosas entidades sobrenaturales, la posible referencia iconográfica a una deidad del inframundo a través de los símbolos de su faldellín y los objetos de carácter bélico que porta el gobernante, sugieren el fuerte carácter del discurso iconográfico expresado en el monumento pétreo cuya finalidad era la de ensalzar al protagonista de la escena.

La carencia de registro jeroglífico en los cartuchos tallados en el monumento dificulta la identificación del personaje representado. Sin embargo, el estudio iconográfico permite aseverar que se trata de un gobernante que está legitimando su autoridad dinástica. Teniendo en cuenta los trabajos iconográficos de Proskouriakoff (1950), el análisis tanto del atuendo como de los objetos portátiles del gobernante permite proponer el marco cronológico del monumento durante el Clásico Tardío. Asimismo, la presencia, por un lado, de entidades zoomorfas sobrenaturales en el tocado que se repiten en otras estelas contemporáneas de Calakmul y, por otro, la posible referencia simbólica a una entidad anímica vinculada con los gobernantes tardíos de Kaan, refuerza la interpretación. En este sentido, se debe recordar que el monumento se encontró en el relleno de la escalera central de la Estructura IV-B, mismo que se llevó a cabo durante la última remodelación del edificio en el Clásico Tardío. Asimismo, la presencia de 
un altar circular con registro jeroglífico, ligado al monumento en este contexto arqueológico, permite sugerir que (dadas sus características formales) pudiera ser una estela o una jamba. Teniendo en cuenta la existencia del complejo conocido como estela-altar, la primera estimación pareciera más acertada. Finalmente, la referencia toponímica de la montaña partida es la misma que se encuentra en la Estructura 10L-22a de Copán (único ejemplo conocido en el corpus jeroglífico), fechada también para dicha temporalidad.

Con base en lo presentado en el artículo, se considera que no se cuenta con la evidencia suficiente para identificar al personaje representado como Tuun K'ab Hix, gobernante temprano de Kaan. Por ello, a partir de los datos expuestos, se propone una posible elaboración del monumento durante un lapso cronológico ubicado en el Clásico Tardío y más concretamente durante el periodo comprendido entre los momentos finales del gobierno de Yuhkno'm Ch'e'n II y el mandato de Yuhkno'm Took K'awiil, gobernantes que ya estaban asentados, fehacientemente, en Calakmul, entre finales del siglo vII y primera mitad del siglo vill d.C.

\section{Bibliografía}

Beliaev, Dmitri, Sergei Vepretskii y Philipp Galeev

2017 "Los textos monumentales en la colección del Museo Nacional de Arqueología y Etnología”, Documentación y análisis de las inscripciones de la colección del Museo Nacional de Arqueología y Etnología, pp. 28-93, Dmitri Beliaev y Mónica de León (eds.). Guatemala: Centro de Estudios Mayas Yuri Knórosov.

Bernal Romero, Guillermo

2012 "El señorío de Palenque durante la era de K'inich Janaahb' Pakal y K'inich Kan B'ahlam (615-702)", tesis de doctorado en Estudios Mesoamericanos. México: Universidad Nacional Autónoma de México.

2014 Glifos enigmáticos de la escritura maya. El logograma T514, YEJ, "filo". Manuscrito inédito en versión larga. México: Universidad Nacional Autónoma de México, Instituto de Investigaciones Filológicas, Centro de Estudios Mayas.

Braswell, Geoffrey, Joel Gunn, María del Rosario Domínguez Carrasco, William Folan, Laraine Fletcher, Abel Morales y Michael Glascock

2004 "Defining the Terminal Classic at Calakmul, Campeche", The Terminal Classic in the Maya Lowlands: Collapse, Transition and Transformation, pp. 162-194, Arthur Demarest, Prudence Rice y Don Rice (eds.). Boulder: University Press of Colorado.

Carrasco Vargas, Ramón

1998 Informe de los trabajos arqueológicos. Proyecto Calakmul, Campeche. Temporada 1997-1998. Tomos I y II. México: Instituto Nacional de Antropología e Historia, Archivo Técnico de la Coordinación Nacional de Arqueología. 
Carrasco Vargas, Ramón

1999 "Actividad ritual y objetos de poder en la Estructura IV de Calakmul, Campeche", Land of the Turkey and the Deer, pp. 69-84, Ruth Gubler (ed.). Lancaster: Labyrinthos.

2000 Informe. Proyecto Arqueológico Calakmul, Campeche. Temporada 2000. Vol. 1. México: Instituto Nacional de Antropología e Historia, Archivo Técnico de la Coordinación Nacional de Arqueología.

2003 "Actividad ritual y objetos de poder en la Estructura IV de Calakmul”, Calakmul: Antología, pp. 149-166, Carlos Vidal y Marilyn Domínguez (comps.). Campeche: Consejo Nacional para la Cultura y las Artes, Instituto Nacional de Antropología e Historia.

Carrasco Vargas, Ramón y Sylviane Boucher

1994 "Calakmul. Espacios sagrados y objetos de poder", Arqueología Mexicana, II (10): 32-38.

Domínguez Carrasco, María del Rosario

2008 Análisis químico y sociopolítico de producción cerámica prehispánica en la región de Calakmul, Campeche. Campeche: Universidad Autónoma de Campeche.

Fahsen, Federico y Arthur Demarest

2001 "El papel del Reino de Cancuén en la historia de las Tierras Bajas Mayas: nuevos datos epigráficos", XIV Simposio de Investigaciones Arqueológicas en Guatemala, pp. 858-874, Juan Pedro Laporte, Ana Claudia Suasnávar y Bárbara Arroyo (eds.). Guatemala: Museo Nacional de Arqueología y Etnología.

Florescano, Enrique

2009 Los orígenes del poder en Mesoamérica. México: Fondo de Cultura Económica.

García Barrios, Ana

2011 "Análisis iconográfico preliminar de fragmentos de las vasijas estilo códice procedentes de Calakmul”, Estudios de Cultura Maya, XXXVII: 65-97. DoI: http://dx.doi.org/10.19130/iifl.ecm.2011.37.14.

García Barrios, Ana y Verónica Amellali Vázquez López

2011 "The Weaving of Power: Women's Clothing and Protocol in the SeventhCentury Kingdom of Kaanu'l”, Latin American Indian Literatures Journal, 27 (1): 50-95.

García Barrios, Ana y Ramón Carrasco Vargas

2006 "Algunos fragmentos cerámicos de estilo códice procedentes de Calakmul", Los Investigadores de la Cultura Maya. Tomo I, pp. 126-136. Campeche: Universidad Autónoma de Campeche.

García Capistrán, Hugo

2017 "Los rostros de la montaña. Desarrollo iconográfico de un símbolo del poder en el área maya y otras regiones mesoamericanas", Piedras y papeles, vestigios del pasado. Temas de arqueología y etnohistoria de Mesoamérica, pp. 

nacantepec: El Colegio Mexiquense, A.C.

2019 "La montaña sagrada. Aspectos sobre la legitimación del poder en el Clásico maya”, Estudios de Cultura Maya, LIII: 139-172. DoI: http://dx.doi.org/10.19130/ iifl.ecm.2019.53.923.

García Capistrán, Hugo y Rogelio Valencia Rivera

2017 “'En el lugar de la hendidura se levanta el árbol florido’. Reconstrucción de un mito maya desde una perspectiva americanista", Del saber ha hecho su razón de ser... Homenaje a Alfredo López Austin, pp. 389-411, Eduardo Mato y Ángela Ochoa (coords.). México: Secretaría de Cultura, Universidad Nacional Autónoma de México.

Grube, Nikolai

2004 "Akan: The God of Drinking, Disease and Death", Continuity and Change: Maya Religious Practices in Temporal Perspective, pp. 59-76, Daniel GrañaBehrens, Nikolai Grube, Christian Prager, Frauke Sachse, Stefanie Teufel y Elizabeth Wagner (eds.). Markt Schwaben: Verlag Anton Saurwein.

Helmke, Christophe y Jaime Awe

2016 "Sharper than a Serpent's Tooth: A Tale of the Snake-Head Dynasty as Recounted on Xunantunich Panel 4", The Pari Jounal, XVII (2): 1-22.

Lister, Robert y Florence Lister (eds.)

1970 In Search of Maya Glyphs, from the Archaeological Journals of Sylvanus G. Morley. Santa Fe: Museum of New Mexico Press.

Marcus, Joyce

1987 The Inscriptions of Calakmul. Royal Marriage at a Maya City in Campeche, México. Ann Arbor: University of Michigan, Museum of Anthropology.

2001 “Textos dinásticos”, Las ruinas de Calakmul, Campeche, México: un lugar central y su paisaje cultural, pp. 37-42, William Folan, Laraine Fletcher, Jacinto May Hau y Linda Florey Folan (coords.). Campeche: Universidad Autónoma de Campeche.

Martin, Simon

2008 "Wives and Daughters on the Dallas Altar", Mesoweb. <www.mesoweb. com/articles/martin/Wives\&Daughters.pdf > [consultado el 13 de febrero del 2020].

Martin, Simon, Vilma Fialko, Alexandre Tokovinine y Fredy Ramírez

2016 "Contexto y texto de la Estela 47 de Naranjo-Sa'aal, Petén, Guatemala", XXIX Simposio de Investigaciones Arqueológicas en Guatemala, pp. 615-628, Bárbara Arroyo, Luis Méndez y Gloria Ajú (eds.). Guatemala: Museo Nacional de Arqueología y Etnología.

Martínez Rosado, Joaquín

1990 Breve historia de la arqueología en Campeche. Campeche: Universidad Autónoma de Campeche. 
Nalda, Enrique, Claude-François Baudez, Erik Velásquez, Simon Martin, Nikolai Grube y David Stuart

2004 Los cautivos de Dzibanché. México: Instituto Nacional de Antropología e Historia.

Nielsen, Jesper y Christophe Helmke

2011 "Reinterpreting the Plaza de los Glifos, La Ventilla, Teotihuacan", Ancient Mesoamerica, 22: 345-370. Dol: https://doi.org/10.1017/S0956536111000289.

Nieves, Lucía, Lourdes Esparza y Paco García Nieto

1995 "Trabajos arqueológicos en la Plaza Central de Calakmul, Campeche, México", Religión y sociedad en el área maya, pp. 93-108, Carmen Varela, Juan Luis Bonor y María Yolanda Fernández (coords.). Madrid: Sociedad Española de Estudios Mayas.

Pallán Gayol, Carlos

2006 "Estudios de caso sobre textos jeroglíficos mayas del registro público de colecciones de México", tesis de licenciatura en Arqueología. México: Escuela Nacional de Antropología e Historia.

Pérez Suárez, Tomás

2000 "Pintores y escultores mayas”, Arqueología Mexicana, VII (42): 60-67.

Proskouriakoff, Tatiana

1950 A Study of Classic Maya Sculpture. Washington, D.C.: Carnegie Institution of Washington.

Ruppert, Karl y John Denison

1943 Archaeological Reconnaissance in Campeche, Quintana Roo and Peten. Washington, D.C.: Carnegie Institution of Washington.

Schele, Linda, David Stuart y Nikolai Grube

1991 "A Commentary on the Inscriptions of the Structure 22A at Copán”, Copán Notes, 98: 1-11.

Šprajc, Iván y Pedro Francisco Sánchez Nava

2012 "Arquitectura y planeación urbana en Calakmul, Campeche, México: astronomía, calendario y geografía simbólica”, XXI Encuentro Internacional Los Investigadores de la Cultura Maya. Tomo II, pp. 95-110. Campeche: Universidad Autónoma de Campeche.

Stuart, David

2012 "Notas en torno a un nuevo texto de La Corona", Mesoweb. <www.mesoweb. com/es/articulos/Stuart/LaCorona.pdf > [consultado el 21 de julio del 2019].

Stuart, David y Stephen Houston

1994 Classic Maya Places Names. Washington, D.C.: Dumbarton Oaks. 
Stuart, David, Marcello Canuto, Tomás Barrientos y Alejandro González

2018 "A Preliminary Analysis of Altar 5 from La Corona”, The Pari Journal, XIX (2): $1-13$.

Taube, Karl

2004 "Flower Mountain. Concepts of Life, Beauty, and Paradise among the Classic Maya”, RES: Anthropology and Aesthetics, 45: 69-98.

Valverde Valdés, María del Carmen

2004 Balam. El jaguar a través de los tiempos y los espacios del universo maya. México: Universidad Nacional Autónoma de México, Instituto de Investigaciones Filológicas, Centro de Estudios Mayas.

Vázquez Campa, Violeta

2014 "Depósitos rituales arqueológicos del periodo Clásico en Campeche”, Estudios de Cultura Maya, XLIV: 167-202. DoI: http://dx.doi.org//10.19130/iifl. ecm.2014.44.122.

Vázquez López, Verónica Amellali

2017 "Pact and Marriage: Sociopolitical Strategies of the Kanu'l Dynasty and its Allies during the Late Classic Period", Contributions in New World Archaeology. Vol. 11, pp. 9-48, Monika Banach, Christophe Helmke y Jaroslaw Zralka (eds.). Cracovia: Universidad de Jagiellonian, Instituto de Arqueología.

Velásquez García, Erik y Carlos Pallán Gayol

2006 "La estela 52 de Calakmul y el reinado de Yuhkno'm Too'k' K'awiil”, Los investigadores de la Cultura Maya, núm. 14, t. II: 340-346. Campeche: Universidad Autónoma de Campeche.

Wagner, Elisabeth

1998 "An Alternative View on the Meaning and Function on the Structure 10l-22a, Copán, Honduras", The Sacred and the Profane. Architecture and Identity in the Maya Lowlands, pp. 25-49, Pierre Colas, Kai Delvendahl, Marcus Kuhnert y Annette Schubart (eds.). Markt Schawben: Verlag Anton Saurwein.

2005 "Nudos, bultos, muertos y semillas: algunas observaciones en torno al título bolon tz'ak(bu) ajaw”, Ketzalcalli, 1: 28-47.

Pablo Alberto Mumary Farto. Español. Licenciado en Historia por la Facultad de Geografía e Historia de la Universidad de Santiago de Compostela, especializado en Estudios Americanos, Patrimonio Documental y Bibliográfico y maestro en Historia de América Latina. Mundos Indígenas por la Universidad Pablo de Olavide, Sevilla, y doctor en Estudios Mesoamericanos por la Universidad Nacional Autónoma de México. Actualmente se encuentra realizando una estancia de investigación posdoctoral en el Instituto de Investigaciones Antropológicas de esta universidad. Su principal línea de investigación es el estudio de las dinámicas 
político-sociales de los señoríos de las Tierras Bajas mayas del periodo Clásico a través de su análisis iconográfico y epigráfico. Su proyecto actual se titula "Rutas terrestres y fluviales en la expansión de la dinastía Kaan. Perpetuando el poder durante el Clásico Terminal". Entre sus últimas publicaciones se encuentran "Un recipiente especial para una bebida peculiar. Análisis de la vasija maya K955", "Ofidios terrenales y sobrenaturales, símbolos de poder de los ajawtaak de Kaan" y Los señores de la serpiente. Poder y organización de la dinastía Kaan, todas como autor único.

pablomumaryfarto@hotmail.com 